\title{
Guerra Fria: uma arqueologia do conceito (e sua atualidade) a partir do ocidente
}

\author{
Cold War: a concept arqueology (and its contemporaneity) from a western perspective
}

Marcos Alexandre Arraes ${ }^{*}$

Palavras-chave:

Guerra Fria

Orientalismo

Alteridade

\begin{abstract}
Resumo: O presente artigo procura revisitar o conceito de Guerra Fria, partindo dos eventos que foram sua condição de possibilidade, para demonstrar os embates políticos e culturais que fundaram uma imagem consolidada do Ocidente em oposição a um outro inferior e ameaçador. Objetivo, assim, ao desvelar a alteridade aqui analisada, contribuir para a compreensão da história do tempo presente, especialmente da contemporaneidade da História do Brasil, onde opostos maniqueístas assentaramse de forma bastante evidente e perigosa. A relação temporal entre esses eventos, contudo, parece evidente e fica a cargo do próprio conceito de Guerra Fria e seus efeitos político-sociais.
\end{abstract}

Keywords:

Cold War

Orientalism

Otherness

\begin{abstract}
This article seeks to revisit the concept of the Cold War starting from the very events that made it possible then demonstrating the political and cultural conflicts that founded a consolidated image of the West as opposed to an inferior and threatening other. Thus, in order to unveil the otherness analyzed here, it is an objective to contribute to the understanding of the history of the present time, especially of the contemporaneity of Brazilian History, where Manichean opposites have settled in a very evident and dangerous way. The continuity and density of these specific discussions, however, remains the responsibility of the reader and of a possible later study. The temporal relationship between these events, however, seems evident and is in charge of the very concept of the Cold War and its long-term political-social effects.
\end{abstract}

Recebido em 03 de dezembro de 2018. Aprovado em 18 de fevereiro de 2019.
Em sua edição de julho de 1948, a revista Seleções publicou uma matéria com o sugestivo título "Cortina de ferro para a Tchecoslováquia". Ali se expõe como o governo do Pós-Segunda Guerra foi organizado naquele país e como se deu a ascensão do comunismo na região. Após três páginas de intensas críticas ao processo político descrito, a conclusão da revista é de que a Tchecoslováquia "[...] prestou um serviço ao mundo, como laboratório de experiência destinada a revelar se o comunismo e a democracia podem governar simultaneamente, no mesmo Estado. A prova teve como resultado a extinção da democracia" (SELEÇÕES READER'S DIGEST, 1948, p. 44-46).
O discurso construído pela revista é apenas a ponta do iceberg de uma política enunciativa muito maior que seria posta em prática no imediato Pós-Guerra e entraria para os anais da história como Guerra Fria. Nesse contexto, um intricado embate entre duas potências com pretensões hegemônicas no cenário internacional se transformaria em uma batalha direta no campo imagético, buscando, cada lado, construir a si como o modelo de civilização por excelência e ao outro como o seu nemesis, expondo seus supostos e inexoráveis defeitos e maldades, fazendo crer, portanto, serem inconciliáveis.

Cinco de março de 1946. Westminster College, Fulton, Missouri, Estados Unidos da

\footnotetext{
* Professor Adjunto do Departamento de História Universidade Federal do Tocantins (UFT). Pós-doutorando em Antropologia Visual na Universidade Federal do Rio Grande do Norte (UFRN). Doutor em História pela Universidade Federal de Santa Catarina (UFSC). E-mail: <maarraes@gmail.com>.
} 
América. Perante uma plateia atenta e repleta de estudantes, professores e estadistas, Winston Churchill faz um pronunciamento pessoal - já que não mais representava a Grã-Bretanha oficialmente ${ }^{1}$ - e de grande impacto para a conjuntura históricopolítica da época. Em seu discurso, o renomado estadista exalta o povo estadunidense, conclama uma união entre os povos de língua inglesa e enuncia, em tom de desafio à plateia - não apenas a imediata, que o ouvia em pessoa, mas todas as nações aliadas ao bloco capitalista - a existência de uma "ameaça e perigo à civilização cristã", ameaça esta que teria dividido o mundo através de uma cortina de ferro baixada sobre a Europa.

Os Estados Unidos estão, neste momento, no auge do poder mundial. É um momento solene para a democracia americana. Com o predomínio do poder vem também uma responsabilidade pesada para com o futuro. Ao olhardes à vossa volta, deveis sentir não só o peso do dever, mas também a preocupação de que possais falhar ao que se exige de vós. A oportunidade está presente, clara e brilhante, para os nossos dois países. Rejeitá-la, ignorá-la ou malbaratá-la atrairá sobre nós a censura dos tempos futuros. É necessário que constância de espírito, persistência de objetivo e a grande simplicidade de decisão guiem e orientem o comportamento dos povos de lingua inglesa na paz, tal como guiaram na guerra. Devemos, e acredito que o faremos, corresponder a essa terrível exigência.

[...] Qual, portanto, o conceito estratégico geral que devemos adotar hoje? Nada menos do que a segurança e o bem-estar, a liberdade e o progresso de todos os lares e famílias de todos os homens e mulheres em todas as terras. [...]

Não podemos estar cegos ao fato de que as liberdades desfrutadas pelos cidadãos de todo o Império Britânico não são válidas em considerável número de países, alguns dos quais muito poderosos. Nesses Estados, o controle é imposto ao povo por vários tipos de governos policiais gerais, a tal ponto que se torna contrário a todos os princípios da democracia.
$\mathrm{O}$ poder do Estado é exercido sem contenções, seja por ditadores ou por oligarquias compactas agindo através de um partido privilegiado e de uma polícia política. Não é nosso dever, neste momento, quando as dificuldades são numerosas, interferir pela força nas questões internas de países que não conquistamos na guerra, mas não devemos deixar de proclamar, sem medo, que os grandes princípios da liberdade e dos direitos do homem, que constituem uma herança conjunta do mundo de língua inglesa e que, através da Magna Carta, da Lei dos Direitos, do habeas corpus, do julgamento pelo júri e do direito civil inglês, encontram sua expressão mais famosa na Declaração de Independência.

Uma sombra desceu sobre o cenário, até bem pouco iluminado pela vitória aliada. Ninguém sabe o que a Rússia Soviética e sua organização comunista internacional pretendem fazer no futuro imediato, ou quais os limites, se os há, de suas tendências expansionistas e de proselitismo.

De Stettin no Báltico até Triste, no Adriático, uma cortina de ferro foi baixada através do Continente Europeu. Atrás dela estão as capitais dos antigos Estados da Europa Central e Oriental. Varsóvia, Berlim, Praga, Viena, Budapeste, Belgrado, Bucareste e Sofia, todas essas famosas cidades e as populações à volta delas estão na esfera soviética sujeitas, de uma forma ou de outra, não apenas à influência soviética, mas a um controle intenso e cada vez mais forte de Moscou. [...]. Os Partidos comunistas, que eram muito pequenos em todos esses estados orientais da Europa, foram colocados num destaque e desfrutam de um poderio muito superior à sua proporção numérica, e buscam obter, em toda parte, o controle totalitário. (CHURCHILL 1946, apud MORRAY, 1961, p 61-68, grifos meus).

Recheado de metáforas bem elaboradas, a clareza do discurso é assustadora. É de uma nitidez 
visual. Contudo, mesmo na versão traduzida ao português, sua força imagética permanece. Como questionar metáforas como "uma sombra desceu sobre o cenário, até bem pouco iluminado pela vitória aliada"? Imediatamente conseguimos visualizar a cena; uma aura escura cobrindo o cenário europeu seja ele o mapa que conhecemos ou as paisagens que nos damos a imaginar. $\mathrm{Ou}$, ainda, a ideia de "uma cortina de ferro foi baixada através do Continente Europeu"? Ela é de uma força explicativa explícita e inquebrável. A expressão não foi uma completa originalidade de Churchill: segundo Sidnei Munhoz (2002), Goebbels, chefe da propaganda nazista alemã, já teria utilizado a mesma expressão nos momentos finais da Segunda Guerra para alertar o povo alemão do perigo dos avanços aliados e sobre a necessidade de proteger o leste europeu, uma vez que a deposição das armas pelos alemães faria descer uma cortina de ferro sobre o território controlado pela URSS e sob a qual nações seriam massacradas. Todavia, é a partir dele que a metáfora imagética ganha força e popularidade. Tanto que deu margem para diversas apropriações, como a charge da famosa personagem do cartunista argentino Quino, a Mafalda:
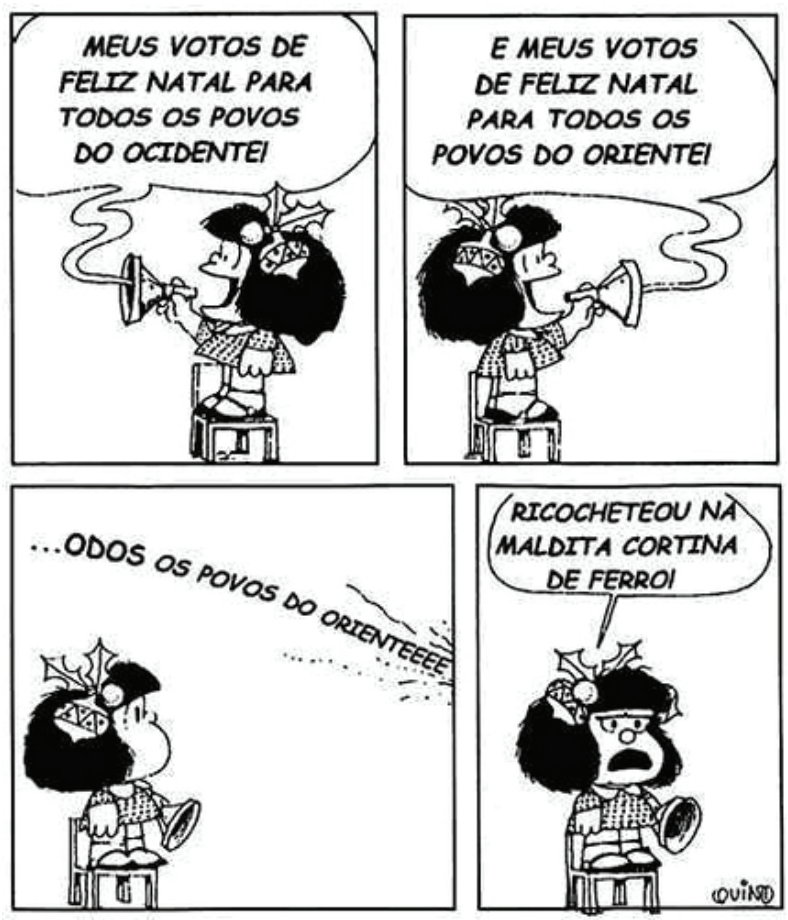

Figura 1: A cortina de Ferro em Quadrinhos Fonte: Tudo sim é história ([s. d.]).
Além da referência à imagem da cortina rígida, dura, baixada no centro da Europa segundo Churchill, a charge ainda faz referência à representação que essa imagem buscava criar: a divisão oriente e ocidente. Divisão esta quase inquebrável - daí a metáfora do ferro - e que não permitia a passagem sequer do som do ocidente para o oriente. Voltarei a esse outros aspectos da fala do ex-Primeiro-ministro inglês mais adiante.

Atento à clareza da mensagem, Stálin, alguns dias depois, rebateria as questões levantadas por Churchill em tom similar por meio de uma entrevista dada à revista soviética Pravda, colocando-se como vítima da iniciativa ocidental e acusando o inglês de incitar o belicismo com apoio de algumas personalidades nos Estados Unidos. Inaugurava-se, assim, o período conflituoso entre as duas grandes potências vitoriosas na segunda guerra. ${ }^{2}$

Pergunta: Como considera o último discurso de Churchill nos Estados Unidos da América?

Resposta: Considero-o um ato perigoso, destinado a semear a dissenção entre os Estados aliados e impedir sua colaboração.

Pergunta: É possível considerar o discurso de Churchill como prejudicial à causa da paz e segurança?

Resposta: Sim, sem dúvida. Na verdade, o Sr. Churchill toma agora a posição dos provocadores de guerra, e nisso não está só. Tem amigos não só na GrãBretanha, mas também nos Estados Unidos [...].

$\mathrm{Na}$ verdade, o Churchill e seus amigos na Inglaterra e nos Estados Unidos apresentam às nações que não falam inglês um ultimato: aceitem voluntariamente nosso domínio, e tudo estará bem; de outro modo, a guerra é inevitável.

Mas as nações derramaram seu sangue no curso de uma sangrenta guerra de cinco anos pela liberdade e independência de seus países, e não para trocar o domínio de Hitler pelo de Churchill. É muito provável, por isso, que as nações que não falam a língua inglesa e que constituem a grande maioria da população mundial, não concordem em se submeter a uma nova escravidão [...]. 
$[\ldots]$

Pergunta: Como considera o trecho do discurso em que são atacados os sistemas democráticos dos Estados europeus que têm fronteira conosco, e as relações de boa-vizinhança estabelecidas entre esses Estados e a União Soviética?

Resposta: Essa parte do discurso do Sr. Churchill está composta de calúnias, descortesias e falta de tato. O Sr. Churchill afirma que "Varsóvia, Berlim, Praga, Viena, Budapeste, Belgrado, Bucareste Sofia - todas essas famosas cidades e as populações em torno dela - estão na esfera soviética e sujeitas, de uma forma ou de outra, não só à influência soviética, mas a um controle intenso e cada vez mais forte de Moscou". O Sr. Churchill considera tudo isso uma "tendência expansionista sem limites” da parte da União Soviética [...].

Em primeiro lugar, é absurdo falar de controle exclusivo da URSS em Viena e Berlim, onde existem Conselhos de Controle Aliados, formados de representantes de quatro Estados, e nos quais a URSS tem apenas um quarto dos votos. Acontece que muita gente não resiste ao desejo de caluniar. Mas tudo tem limites.

Em segundo lugar, é preciso não esquecer as circunstâncias seguintes: os alemães invadiram a URSS através da Finlândia, Polônia, Romênia, Bulgária e Hungria. Os alemães puderam invadir tais países porque, na época, neles existiam governos hostis à União Soviética. Em consequência da invasão alemã, a União Soviética sofreu perdas irreparáveis na luta, que juntamente com a ocupação alemã e a deportação de cidadãos soviéticos para a Alemanha, se elevam a cerca de sete milhões de pessoas. Em outras palavras, as perdas da União Soviética foram várias vezes maiores do que as da Grã-Bretanha e dos Estados Unidos juntos. É possível que em certos círculos haja uma tendência para esquecer esses sacrifícios colossais do povo soviético que contribuíram para a libertação da Europa do jugo de Hitler. Mas a União Soviética não pode esquecê-los. Portanto, não há nada de surpreendente no fato de que a União Soviética, preocupada com sua segurança futura, procure fazer com que existam em tais países governos de atitude leal para conosco. Como pode alguém, de boa mente, considerar essas aspirações pacifistas da URSS como tendências expansionistas?

O Sr. Churchill afirma ainda que "os partidos comunistas [...] buscam, em toda parte, obter controle totalitário. Governos policiais predominam em quase todos os casos e, até agora, com exceção da Tchecoslováquia, não há uma verdadeira democracia”.

Todos sabem que o governo do Estado na Grã-Bretanha, no momento, está nas mãos de um partido, o Trabalhista, e os partidos da oposição não têm o direito de participar daquele governo. É a isso que o Sr. Churchill chama de verdadeira democracia.

A crescente influência dos comunistas não pode ser considerada como fortuita. É coisa perfeitamente lógica. A influência dos comunistas cresceu porque, no período do domínio fascista na Europa, eles se mostraram dignos de confiança, destemidos, prontos ao sacrifício, na luta contra o regime fascista pela liberdade dos povos. [...] (STALIN 1946, apud MORRAY, 1961, p. 68-73, grifos meus).

Ressalta-se que aqui a fala também é imagética, ainda que em outro sentido. Não é possível perceber a mesma nitidez pictórica da mensagem do estadista inglês. Contudo, alguns trechos merecem destaque. Stálin faz uso do mesmo discurso existente nas Américas de uma guerra sanguenta pela liberdade, lembrando que a URSS também fez parte nesse jogo. Assim, ele procura colocar as democracias liberais como "a nova escravidão", comparável aquela sob o regime hitlerista, nos fazendo ponderar quais os alcances e limites do conceito de liberdade, já que presente em ambos os lados agora rivais. $\mathrm{O}$ discurso busca nos convencer do sacrifício soviético durante a guerra, suas perdas humanas e materiais, seus esforços na busca desse tão desejado mundo livre. Ele se utiliza da aliança prévia com os aliados e dos discursos elaborados naquele momento para jogar a culpabilidade do conflito para o lado ocidental, levando-nos, 
de forma convincente, ao menos ao primeiro olhar, a visualizar a URSS como vítima das nações ocidentais: foi a existência de governos hostis a União Soviética que fez com que a guerra chegasse em vosso solo, causando tamanha destruição. Diante disso, foram obrigados a reagir e o fizeram não apenas para se salvar, mas, mesmo após perdas inestimáveis, avançando nos campos de batalha em socorro das potências ocidentais. Enfim, partindo dos elementos principais do discurso do Churchill, Stálin constrói a imagem do ocidente como prepotente, que se entende superior em sua civilização, em última instância, agressor, e que cabe a URSS o papel de reagir a essa ameaça.

Ameaça e perigo, portanto, são a tônica do imaginário erigido na guerra discursiva entre os estadistas. Então, inauguraram-se as bases da construção mental sobre a qual o mundo iria viver nas décadas seguintes: a ameaça comunista, para o caso das democracias liberais; e a ameaça imperialista do capital e da guerra, para o caso do socialismo soviético. Restava às nações, em suas políticas, agir dentro desse escopo imagético, protegendo-se e resguardando-se contra os perigos iminentes de cada lado na conjuntura bipolar. Sugiram, assim, o discurso da segurança e as políticas que, em nome desta, justificavam as mais diversas demonstrações de hegemonia em ambos os lados do globo.

Vê-se, portanto, a força dos discursos enquanto produtores de imagens. Foi através dessa força constitutiva que a metáfora da cortina de ferro tornou-se expressão corriqueira, rapidamente se popularizando e sendo utilizada nos mais diversos meios sociais do mundo ocidental. Junto com ela, também foi endossada nesses mesmos meios a mensagem que se buscava clarificar, ou seja, a repartição do mundo por uma barreira dura, intransponível, onde nada conseguia passar de cá para lá, nem deveria passar de lá para cá. Ocorreu a divisão entre dois lados incomunicáveis: um progressista e defensor da liberdade; outro perigoso e insistente no totalitarismo. É o caso, por exemplo, da matéria de Seleções discutida anteriormente, a qual endossou a ideia da Guerra Fria pelo conceito elaborado por Churchill, apresentando a democracia como um valor superior e o comunismo como um oposto inconciliável.

Essa seria a tônica do conflito. Apenas um ano após o pronunciamento em Fulton, o então presidente dos Estados Unidos, Harry Truman, anunciaria ao congresso do seu país um conjunto de medidas que seguiam as linhas gerais da mensagem do aliado inglês e seriam unificadas sob o epíteto de Doutrina Truman. Anunciava-se ali a criação do Programa de Reconstrução Europeia - ou Plano Marshall, como ficou mais comumente conhecido que concedia empréstimos a juros baixos, injetando dólares nos países europeus que aceitassem as condições do acordo, visando à recuperação desses países após a devastação proporcionada pelos bombardeios anos antes. ${ }^{3}$ Associada a essa iniciativa de fundo mais prático, o discurso do presidente inaugurava também uma política sistemática de limitação do campo de possibilidades de expansão da influência soviética e do comunismo de uma forma geral que ficou conhecida como Política de Contenção (Containment Policy).

Contenção foi uma distinta estratégia ideológica da Guerra Fria. Tomando por base as preocupações dos EUA com a balança de poder no que diz respeito à relação com a União Soviética, ela propunha um conflito de soma zero entre Moscou, que figurava como agressiva e expansionista, e Washington, que figurava como defensiva e pacífica. A Contenção sustentava que, já que a cooperação com os soviéticos era impossível e que todos os governos comunistas eram subservientes a Moscou, a expansão do comunismo em qualquer parte do mundo representava uma ameaça direta à fração de poder mundial dos EUA. [...] Depois do discurso da Doutrina Truman, a Contenção se tornou um dos objetivos centrais da política externa do pós-Guerra. (KLEIN, 2003, p. 24). ${ }^{4}$

Com a estratégia da Contenção, portanto, a política externa estadunidense buscava aliar a prática de combate ao comunismo a uma justificativa ideológica bem específica: o conflito entre dois projetos de civilização e poder. Dava-se 
sentido, assim, não apenas ao Plano Marshall, como também a todas as políticas de combate ao comunismo, que eram anteriores a esse momento, mas ganhavam agora novo suporte estatal através de uma discursividade específica ao período do PósGuerra.

$\mathrm{Na}$ esteira dessas decisões, outra política faria ecoar um dos elementos do discurso de Churchill proferido anos antes: a busca de uma unidade imaginária entre os países líderes do bloco capitalista. De uma comunhão linguística - os países de língua inglesa - anunciada pelo estadista, passouse a enunciar a ideia de comunhão atlântica, que seria composta não apenas de aparatos econômicos, mas também militares e, especialmente, culturais. A mudança não ocorreu sem propósito. A imagem presente no discurso de Fulton, Missouri, de uma comunhão racial baseada em uma língua comum, $\mathrm{o}$ inglês, possuía em si certa arrogância e, na busca de potência, considerava as forças políticas nacionais do momento do seu pronunciamento, quando a Alemanha estava destruída sem qualquer vislumbre de uma retomada significativa às hostes do poder, e a França perdia terreno na geopolítica europeia. As mudanças que ocorreriam nos anos seguintes, no entanto, exigiam um conceito mais amplo, menos excludente e que abarcasse os principais aliados na nova estrutura de poder mundial, vislumbrando-se, então, a construção de uma comunidade atlântica, na qual se fundariam diversas iniciativas de ajuda mútua e partilha de responsabilidades na gestão da recém-formada política mundial sob a liderança e supervisão dos Estados Unidos.

Um importante passo para dar corpo e legitimidade a essa pretensa comunidade foi $o$ lançamento, em 1949, da Organização do Tratado do Atlântico Norte (OTAN), funcionando como o organismo político-militar da comunidade atlântica. A fundação dessa organização não foi tão simples, no entanto, e merece maior atenção.

O Plano Marshall, em certo sentido, feria a moral das potências europeias decadentes, que haviam se acostumado a dar as cartas no cenário internacional e viam-se agora em situação subalterna, o que gerava desconforto e oposição não apenas em setores dos governos dos países envolvidos, mas entre grupos específicos da população, que defendiam a busca de uma saída nacionalista e local para a crise (SAUNDERS, 2000). Além disso, o continente havia sido dividido por uma guerra, e certo revanchismo ainda não havia sido totalmente liquidado. Portanto, a ideia de partilhar uma economia, valores, ideais com recentes rivais e ainda, em certo sentido, em um papel de subserviência diante da liderança de uma potência alheia à região, não era muito popular.

$\mathrm{Na}$ tentativa de combater esse sentimento, algumas tentativas de promoção da alternativa proposta pelos EUA foram postas em prática antes e depois da assinatura efetiva do acordo. Entre elas, a mais notória e de mais efeito foi o concurso intraeuropeu de cartazes realizado em 1950 em Paris, no qual artistas dos 13 países que aceitaram o plano eram convidados a criar pôsteres com base no tema "cooperação intraeuropeia para um melhor padrão de vida" (SAUNDERS, 2000), com o objetivo de promover um sentimento comum entre as nações que, havia pouco, tinham estado em lados opostos de uma guerra. Mais de dez mil obras foram enviadas para o júri técnico em Paris e destes, 25 foram selecionados e expostos em galerias pelo continente. ${ }^{5} \mathrm{Na}$ Figura 2, podemos visualizar uma dessas imagens, onde a união entre os membros europeus é simbolizada por um catavento em que cada pá representa um país através de sua bandeira nacional. Ainda que de forma distante, compondo uma pá externa do cata-vento, também estão presentes os Estados Unidos, pertencendo ao mesmo grupo que forma a fonte de energia, cada nação desempenhando o seu papel. A legenda sela a mensagem: "qualquer que seja o tempo, nós apenas chegamos ao bem-estar JUNTOS”. A união ainda é colocada em um pedestal e todo o seu entorno é obscuro e sombrio. Ou seja, fora da união, incertezas e nebulosidade. $\mathrm{O}$ plano de reconstrução era a certeza da vitória. Isso é ainda mais significativo se levarmos em consideração que era um discurso produzido por europeus, ainda que seguindo as diretrizes do concurso. 


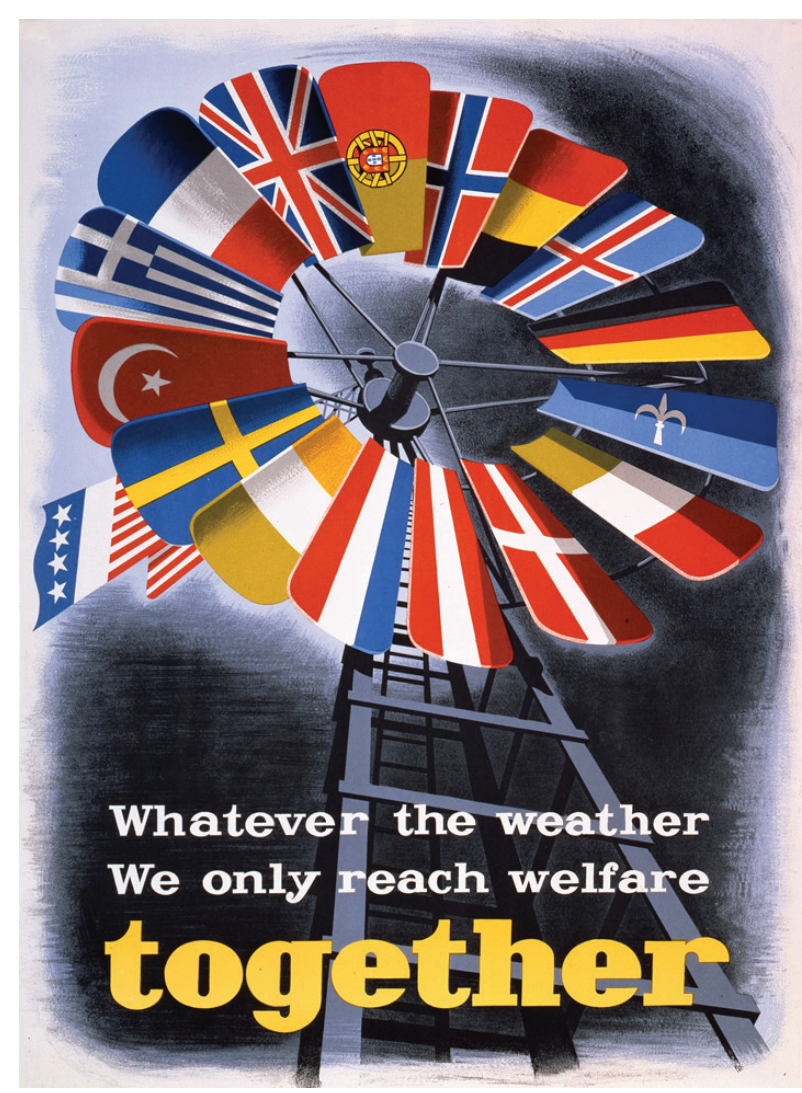

Figura 2: Cartazes do Plano Marshal

Fonte: Marshall (2014).

Dessa forma, o Plano de Reconstrução Europeu facilitou não apenas a integração econômica, mas também promoveu a ideia de uma partilha de interesses comuns primeiramente entre os países europeus e, extensivamente, com os Estados Unidos. Os passos que seriam seguidos a partir daí demonstram esse caminho: em março de 1948, Grã-Bretanha, França, Bélgica, Holanda e Luxemburgo assinam o tratado de Bruxelas, que assegurava a defesa coletiva em caso de agressão externa a quaisquer membros do acordo. Já em maio do mesmo ano, o senador estadunidense Arthur Vandenburg propôs a criação de um tratado de segurança com os países europeus aliados aos EUA, tratado este que deveria aderir às regras internacionais da ONU, mas possuir existência independentemente do Conselho de Segurança da ONU, onde a URSS possuía poder de veto (MORRAY, 1961). Nos meses subsequentes, intensas negociações teriam lugar com o objetivo de definir os termos do acordo e as questões de financiamento da estrutura da organização, para, finalmente, em abril de 1949, ser assinado o Tratado de Washington, que criava o North Atlantic Treaty Organization (NATO), ou Organização do Tratado do Atlântico Norte (OTAN). Dava-se, assim, corpo e visibilidade ao bloco ocidental, pois, tal como colocou Paul Kennedy (1989, p. 362): “[...] a aliança da OTAN fez militarmente o que o Plano Marshall tinha feito economicamente: aprofundou a divisão da Europa em dois campos", o democrático liberal e o socialista soviético".

Uma dificuldade semelhante à implantação do Plano Marshall também iria ser vivenciada por esse novo organismo internacional. Por parte dos europeus, muitos protestavam contra o que se considerava ser um "imperialismo estadunidense". Já entre determinados setores da sociedade estadunidense, existia a resistência de alguns cidadãos em utilizar o dinheiro de seus impostos para a defesa da Europa.

J. Walter Thompson ficou encarregado da publicidade da OTAN durante o delicado período de 1956 a 1959, quando a Organização do Tratado do Atlântico Norte passou por uma crise de identidade diante do protesto dos cidadãos dos Estados Unidos contra os custos de defender a Europa e do início dos protestos europeus contra o imperialismo dos Estados Unidos. A recomendação de JWT foi que esse "escudo da liberdade" buscasse uma nova imagem, uma que, visando ao vindouro décimo aniversário da OTAN, em 1959, iria transformar a "aliança" em "comunidade". Assim, a publicidade iria "tornar claro para o mundo a devastadora superioridade, tanto moral quanto material, da concepção ocidental de Homem e da sua dignidade". O aniversário da OTAN, a música da OTAN, e os slogans promocionais da OTAN, tais como "Boa noite - durma bem - a OTAN permanece em guarda", "OTAN, quatro letras que significam PAZ" e "Desde a OTAN, nem uma polegada de território perdido" iriam funcionar "para forjar uma história de comunidade e tradição". (DE GRAZIA, 2005, p. 238).

Entretanto, uma comunidade não se faz apenas de aparelhos econômicos e militares. Faz-se necessário também construir um laço de 
pertencimento e comunhão de interesses, valores e ideais de forma a cimentar e dar identidade a esse grupo. Em outras palavras, é preciso construir uma comunidade imaginada (ANDERSON, 2008) , $^{6}$ ligada não por apenas uma língua comum $^{7}$ afinal, o alvo desse discurso incluía cerca de uma dezena de línguas, sem contar inúmeros dialetos - mas também por pensamentos, atitudes e um sentimento de comunhão. Era preciso, em última instância, a construção de si. E, como nem todos fazem parte desse grupo, o outro também passa a ser elaborado e edificado em discursos opostos, em uma permanente alteridade.

Um dos esforços nesse sentido foi o Congress for Cultural Freedom (CCF), que começou a funcionar efetivamente em 1951, mas possui uma história prévia. Em março de 1949, o Waldorf Astoria Hotel em Nova Iorque, foi palco de um evento um tanto esquisito para esse cenário: a Conferência para a Paz Mundial, organizada por intelectuais de esquerda, muitos dos quais adeptos do socialismo e outros ainda simpatizantes do regime estalinista. O objetivo era discutir ideias e caminhos para uma paz mundial entre as duas potências, uma vez que a Guerra Fria já havia se tornado uma realidade e atritos mais sérios ocorridos no ano anterior, como o bloqueio de Berlim ${ }^{8}$, puseram em xeque a paz entre os dois blocos hegemônicos. No mesmo espectro, Stálin havia assumido, desde o discurso de Churchill, uma postura defensiva internacionalmente, acusando o bloco capitalista de ser o grande promotor da discórdia com o lado soviético e, para coroar essa postura, passou a encabeçar uma campanha pela paz. Desconfiados das intenções soviéticas, intelectuais do bloco ocidental, liderados pelo filósofo Sydney Hook, um ex-comunista, professor na Universidade de Nova Iorque e editor de da revista socialista The New Leader, organizaram-se para tentar roubar a cena na conferência. O grupo de Hook se autodenominou de Americans for Intelectual Freedom (Americanos Pela Liberdade Intelectual $)^{9}$ e passou a assediar os membros da delegação soviética com perguntas constrangedoras, além de promover um comício noturno em área próxima ao do evento. A estratégia ganhou notoriedade e virou manchete dos jornais dos dias seguintes. A partir dali, membros do governo estadunidense, especialmente da divisão de coordenação de políticas da CIA (Office of Policy Coordination) passaram a se interessar pela atividade e organizaram uma conferência para contra-atacar as reuniões em nome da paz mundial do ano seguinte, que teria lugar em Paris. Reuniram um grupo de intelectuais de esquerda para uma série de palestras de cunho anticomunista. A ideia era mostrar que o comunismo - na época confundido com estalinismo, como veremos no capítulo a seguir - desagradava até mesmo a esquerda bem informada. No entanto, diferentemente do ocorrido em Nova Iorque, a contraconferência não foi tão satisfatória, pois se notou tardiamente que entre os intelectuais anticomunistas havia também um grande sentimento antiamericanista. Após longas discussões e disputas internas de poder, Sydney Hook e seus aliados do governo estadunidense conseguiram convencer a CIA a apoiar secretamente uma nova conferência que teria lugar em Berlim. O local foi escolhido estrategicamente. Enquanto em Paris a esquerda possuía uma tradição de formar uma via própria, sem vincular-se a arregimentações externas, e alguns intelectuais, como J. P. Sartre e Merleau-Ponty, se recusavam a criticar a URSS, Berlim estava sitiada e possuía severas críticas e ressentimento para com os soviéticos. Assim, entre 26 e 29 de junho de 1950, a cidade dividida seria palco do Congress for Cultural Freedom, com um total de 118 participantes para debater temas como Ciência e Totalitarismo, O Artista e a Liberdade, O Cidadão em uma Sociedade Livre e A defesa da Paz e Liberdade. Nomes como Arthur Schlesinger Jr., Bertrand Russel, James Dewey, Karl Jaspers, Benedetto Croce participaram do evento. $\mathrm{O}$ argumento principal foi de que no ocidente havia liberdade de pensamento, até mesmo para criticar o capitalismo, se assim se desejasse. O sucesso foi estrondoso. A partir dali, o grupo organizador da conferência passou a compor um escritório permanente, com sede em Paris e financiamento secreto da CIA (SAUNDERS, 2000), para promover os ideais comuns do bloco capitalista, o sentimento de comunhão entre eles, o respeito à liberdade intelectual e às diferenças de pensamento que 
compõem uma comunidade e também construir propaganda de cunho antissoviético através de diversas revistas editadas para esse fim, entre elas Der Monat, Preuves, Encounter Cuadernos e Tempo Presente, buscando atingir o maior número de leitores possível em diferentes partes do bloco ocidental. Mesmo após a publicação dos vínculos da instituição com a CIA, ela manteve suas atividades por mais alguns anos, perdendo paulatinamente a credibilidade e sendo finalizada em meados da década de $1960 .{ }^{10}$

Vê-se, portanto, a busca de construção de uma comunidade imaginada do bloco ocidental de uma forma bem elaborada, iniciada por projetos concretos de viés econômico e militar suportadas por discursos de unidade e comunhão de interesses e valores que ajudaram a selar o que hoje chamamos de mundo ocidental. O conjunto dessas iniciativas permitiu ver e dizer o bloco ocidental enquanto um espaço se não coeso, ao menos comum, que partilhava, ideias, projetos de civilização, sonhos. Isso demonstra o poder dos conceitos como formados por e formadores de imagens; afinal, foi a partir delas que se conseguiu forjar o sentimento de pertença comum e consolidar-se o imaginário dos mundos apartados na Guerra Fria.

Dando ainda mais materialidade a esse imaginário, foi criado, na administração Eisenhower, o People-to-People program, com o objetivo de angariar o apoio da opinião pública para o internacionalismo da Guerra Fria e, assim, reforçar o sentimento do "nós". De acordo com Klein (2003, p. 49), essa era

[...] uma tentativa de fazer a ideia de interdependência internacional ganhar vida no imaginário popular. Os criadores do programa também o viam como um meio de direcionar algumas das questões que se faziam os formuladores de políticas desde o início da Guerra Fria: como nos podemos "esquentar" a Guerra Fria de forma a criar um apelo aos "corações" estadunidenses? Como podemos transformá-la em uma cruzada positiva? Como podemos encorajar os estadunidenses a abandonar seu prolongado isolacionismo e aprender a se verem em relação com outras pessoas ao redor do mundo? [...] Em última instância, o programa foi um esforço no sentido de dar ao imaginário global de integração uma fundação material, institucional.

O programa consistia em uma integração de mais de 40 comitês que promoviam o contato entre estadunidenses e pessoas em todo o mundo de acordo com interesses em comum em questões cotidianas, como comitês de leitura para estimular a troca de livros e discussões, comitês para colecionadores de selos e outros hobbies, comitês musicais etc. Um exemplo dessas iniciativas foi a produção, através de um comitê para cartunistas, de um livreto de mais de cem páginas ensinando aos turistas estadunidenses como se comportar no exterior. Ou seja, buscava-se agenciar as trocas culturais dentro de um determinado sentido ou padrão desejado; as pessoas deveriam se portar, agir e até mesmo divertir-se de forma concertada, ajudando assim na construção de um sentimento de pertença comum, de um "nós".

Uma iniciativa mais ousada nesse sentido foi a busca da diplomacia estadunidense em unir esforços no sentido de divulgar o American way of life como grande paradigma mundial a partir de demonstrações práticas e comparativas da cultura que tinham como superior e o modo de vida que o comunismo proporcionava. Um passo nessa direção foi a assinatura de acordos culturais com a União Soviética em fins da década de 1950. Entre as ações deste acordo, houve a realização de feiras de exposições científicas, tecnológicas e culturais, incluindo aí moda, hábitos cotidianos e, em especial, produtos industrializados, tanto nos Estados Unidos como na União Soviética. Com isso, o governo estadunidense buscava não só convencer o público visitante de que seu modelo era mais livre - fato que se comprovava pela variedade de produtos culturais e de consumo proporcionada pelo livre mercado - mas também provocar a derrocada do modelo soviético por dentro, pela sedução do consumo.

Uma vez assinado o acordo, a primeira feira ocorreu em junho de 1959, com uma exposição soviética no New York Coliseum. Para a abertura da 
feira, Khrushchev enviou seu Primeiro-ministro, Frol Kozlov para mostrar a Eisenhower e seu vice, Nixon, cópias do Sputnik, lançado anos antes, e de cápsulas espaciais, além de

[...] "maquinaria pesada, um modelo de um quebra-gelo nuclear ('É nisso que usamos a energia atômica'), e muitas peças de arte do realismo socialista glorificando o regime, mas eles também viram moda, peles, pratos e artigos de vidro, o modelo de um apartamento de um trabalhador mobiliado em um estilo ultramoderno, modelos de televisores, carros moscovitas com mais cromo que o Buick 1959, e corredores, e mais corredores de lavadoras e geladeiras".

Em declarações oficiais explicando a escolha das exibições, os russos pareciam quase arrependidos de trazer tantas amostras de Sputnik-e-produtossiderúrgicos para Nova York, já que seu objetivo era no futuro, no qual um país agrário propunha se transformar em um refúgio do consumo. (MARLING, 2000 , p. 258).

Apenas um mês depois, em julho de 1959, seria a vez da Feira de Moscou, palco do famoso Kitchen Debate (MARLING, 2000). ${ }^{11}$ Nada menos do que 5 milhões de dólares foram gastos para promover a exposição - em grande parte investidos pelas grandes corporações, já que o Congresso estadunidense vetou uma grande soma dos verba pública que havia sido solicitada para esse fim. Ali, o visitante poderia se deparar com exibições de moda, estandes de produtos de beleza, quiosques de comida com distribuição gratuita de Pepsi-Cola produto que foi consumido à taxa de dez mil copos por hora durante os 42 dias da feira! - além de modelos de supermercados, casas pré-fabricadas e, especialmente, da cozinha estadunidense.

Para Richard Nixon, as novidades de consumo para a cozinha representava os princípios fundamentais do American way of life. Liberdade. Liberdade do trabalho maçante para a dona de casa. E democracia, a oportunidade de escolher o melhor modelo de uma oferta ilimitada de cores, características e preços que o livre mercado tinha a oferecer. Para Nikita Krushev, toda a exibição estadunidense era uma amostra do excesso lamentável e da trivialidade burguesa. Onde estavam as demonstrações científicas, os Sputniks estadunidenses? "O que é isso?", perguntou o jornal Izvestia. "Uma exibição nacional de um grande país ou uma rede de lojas de departamento?". (MARLING, 2000, p. 243).

Os Estados Unidos acreditavam na força sedutora do seu modo de vida, e investiam pesado para convencer o mundo, incluindo os domínios soviéticos, de que esse era o melhor modelo a ser seguido. Confrontando seus produtos e seu cotidiano com aqueles existentes do outro lado do planeta, eles se propunham tanto a plantar uma semente de discórdia entre os habitantes do mundo soviético, mostrando suas "maravilhas modernas", como a consolidar a escolha do mundo ocidental pelo American way of life.

\section{Casas modelo e supermercados dramatizavam os benefícios da produção em massa para a família média estadunidense. Dessa forma, eles foram sempre importantes dispositivos de propaganda da Guerra Fria, oferecendo provas tangíveis e convincentes da superioridade do sistema econômico que tão casualmente lançava maravilhas para economizar esforço, jantares congelados (carne e batata frita), e agradáveis salas de estar mobiliadas pela House Beautiful. (MARLING, 2000, p. 245).}

Em resumo, a Guerra Fria cultural impulsionou o forjamento de uma cultura pretensamente global com base no American way of life com vistas a combater a expansão do projeto civilizador comunista representado pela União Soviética através de um conjunto extremamente bem articulado de ações.

Washington criou uma variedade de programas de diplomacia cultural que fomentou conexões intelectuais para além das fronteiras nacionais e encorajou sentimentos positivos com relação aos EUA. Esses programas introduziram o mundo a pintura 
abstrato-expressionista, enviou músicos de jazz em turnês e disponibilizou livros estadunidenses através das bibliotecas da USIA. O programa people-to-people surgiu desse esforço de diplomacia cultural: ele era destinado a um público internacional e objetivado para espalhar a cultura, valores e ideias estadunidenses no exterior. Ele procurava criar uma oposição à propaganda Soviética através da promoção de encontros cara a cara entre estadunidenses e pessoas de outros países e, assim, mostrar como os Estados Unidos "de fato" eram. (KLEIN, 2003, p. 50).

O sucesso desse bloco de ações seria inconteste. $\mathrm{O}$ forjamento do Bloco Atlântico constituiu-se na base do que se passou costumeiramente, alguns anos depois, a chamar mundo ocidental, que teve por base o modelo civilizatório estadunidense, incorporando seu estilo de vida, assentando a base da "visi-dizibilidade" do que se entende por cultura ocidental, comunidade imaginada que persiste até nossos dias. Vê-se, assim, como um conjunto bem articulado de práticas discursivas instituíram imagens fundantes de um projeto de civilização que coordena o modo de viver de um considerável grupo de pessoas até a atualidade. Foi justamente a força desse discurso que possibilitou a construção imagética do "nós" e do outro na divisão do mundo em duas esferas distintas não apenas de poder, mas de ser e perceber (n)o mundo, pois essas imagens constituíram identidades e subjetividades, limitando o alcance dos sonhos e projetos de futuro possíveis enquanto foram vigentes.

O escopo de ação da Guerra Fria ideológica não ficou restrito apenas à área de dentro dos muros da comunidade imaginada. Ela também foi travada na disputa por áreas do globo onde se buscaria arregimentar os países da periferia do sistema bipolar para dentro de sua esfera de influência. Não é casual, nesse sentido, o despertar de um extremo interesse por aspectos da vida e cultura asiática durante os anos de 1945-1961 dentro dos Estados Unidos, fato descrito com maestria por Cristina Klein em Cold War Orientalism (2003). Nesse período, segundo essa autora, filmes, revistas, séries fotográficas, livros de turismo, reportagens em frequência alarmante entre outros aspectos culturais voltariam seus olhares para a Ásia na busca de compreender melhor como viviam e pensavam os habitantes daquela parte do globo.

Esse novo olhar para o leste se justificava pela crescente consciência da importância estratégica do continente asiático - e, em menor grau, o africano - no período em questão. Livrandose das amarras imperiais iniciadas em sua maioria no século anterior, ambos os continentes buscavam um espaço dentro do novo sistema internacional onde pudessem construir uma nova identidade e promover seus processos de desenvolvimento independentemente das amarras coloniais dos países capitalistas. E, nesse contexto, a ideia do comunismo soava mais apropriada aos ouvidos das forças políticas nacionais que desejavam reformas profundas. Instava ao bloco capitalista agir dentro da política de contenção e conquistar as mentes e os corações dessas novas nações para o seu núcleo de poder, sendo, portanto, os países do bloco asiático importantes peças desse jogo.

Em perfeita simbiose com o momento de uma renovada produção de bens culturais em seu país, o governo estadunidense iniciou um esforço de promoção da Ásia mediante programas de intercâmbio, treinamentos de pessoal diplomático e técnico para melhor compreensão dos assuntos asiáticos, no qual, evidentemente, a educação teria um papel de destaque. Tal fato fica claro no discurso proferido por Francis Wilcox, um funcionário do Departamento de Estado, para uma plateia de educadores na Filadélfia, em 1957. Como descreve Klein,

Wilcox enfatizou o profundo efeito que a descolonização estava tendo nos Estados Unidos. Ele começou descrevendo a crescente influência das novas nações asiáticas e africanas e a subsequente transformação da Guerra Fria de um plano militar para o ideológico. Ele explicou que a União Soviética, que em fins da década de 40 e início da década de 1950 tinha "expandido seu império" para a China, Coreia e Indochina através do uso da força, estava agora mudando para uma 
"intensa guerra de ideias, ideologias, propaganda e subversão" elaborada para ganhar a confiança dos povos em descolonização através de meios pacíficos. [...] Ele instou sua audiência de educadores a ajudar no treinamento da nova geração de estadunidenses para o seu "novo papel" de liderança mundial através de lições sobre países como Indonésia, cuja localização estratégica e vastos recursos naturais a tornavam de grande valor para ambos: soviéticos e EUA. (KLEIN, 2003, p. 21).

A Guerra Fria, portanto, como procurei antecipar, nada tinha de fria no campo ideológico. Houve, sim, um embate direto entre as duas potências rivais na construção de uma autoimagem positiva e no convencimento das potências emergentes - nos espaços ainda em disputa e mesmo nos já arregimentados para uma ou outra esfera de influência - de que o seu projeto civilizador era o mais positivo.

Neste ponto, quero propor aqui uma aproximação com o conceito de orientalismo muito bem desenvolvido por Edward Said em sua obra homônima (SAID, 2007), onde ele sugere que o exercício do poder imperial europeu sobre o oriente foi pautado e mesmo justificado nas representações que se faziam daquela região. Assim, segundo Said, o orientalismo foi um discurso ocidental estruturado em uma ideologia da diferença na qual o ocidente e o oriente eram elaborados como entidades internamente coerentes e mutualmente excludentes. Em outras palavras, o orientalismo foi uma política de enunciação ocidental do oriente guiada por uma lógica binária de construção do "nós" e do "eles", que são entendidas como essências autoevidentes e necessariamente opostas entre si, sendo uma delas superior e a outra a ela subordinada. Tais práticas enunciativas do outro justificaram, ainda e acordo com Said, a dominação europeia nos países Asiáticos durante o século XIX e parte do XX.

Destarte, tal como a construção do oriente se deu de forma a corroborar o projeto político e civilizador europeu no século XIX, enquadrandose em uma questão da alteridade, ou seja, de uma construção de si a partir de uma definição do seu outro, a construção do mundo atlântico também fez parte de uma política enunciativa de elaboração do bloco hegemônico ocidental com vistas à construção de uma aliança identitária de oposição a um outro a ser desqualificado e combatido. ${ }^{12}$

Com isso, vemos a importância de se entender as estruturas simbólicas da Guerra Fria sendo elas tão ou mais importantes que as questões políticas, militares e econômicas geralmente priorizadas pela historiografia do tema - pois é nessa esfera que se fundam os modos de ver, perceber e agir dos sujeitos históricos. Em outras palavras, é por meio do simbólico que são organizados os modos de agir no universo histórico; é a partir de um conjunto cultural simbólico que decisões políticas são tomadas, que subjetividades são formadas ou que, como nos diz Chartier, "[...] os dominados aceitam ou rejeitam as identidades impostas que visam a assegurar e perpetuar seu assujeitamento" (CHARTIER, 2002, p. 11).

\section{Notas}

1 Winston Churchill havia sido Primeiro-ministro britânico entre maio de 1940 a 1945, quando seu partido, o Conservador, perdeu as eleições para o Partido Trabalhista, assumindo então o posto de Primeiroministro Clement Attlee.

2 Não estou, com isso, querendo afirmar que a Guerra Fria foi ocasionada pelo discurso de Winston Churchill. Os eventos e conjunturas que levaram ao conflito são muito mais complexos e enraizados que a potência discursiva de um único sujeito. O impacto do pronunciamento do inglês, ainda que de grande monta, limita-se à inauguração de uma nova era de transparência nas intencionalidades dos atores internacionais. Se, até ali reinava um clima idealista, personificado na figura de F. D. Roosevelt, ainda que sem grande apoio dos outros líderes ocidentais e em seus últimos suspiros, o realismo inglês varreria para longe o chamado "espírito de Yalta" e, com ele, as tentativas de uma conciliação pelo princípio da justiça nas relações internacionais.

3 Para uma compreensão mais profunda do Plano Marshall, precisa-se interpretá-lo no conjunto das tentativas de reorganização da economia mundial do Pós-45. Cada vez mais integradas com os processos de industrialização, a economia capitalista necessitava de um ajuste mútuo para evitar uma nova crise como a vivida em 1929, quando uma crise no mercado de capitais estadunidense levou à recessão diversos países integrados na economia de mercado. Não tendo sofrido ataques em seu território e sendo o principal fornecedor de guerra dos Aliados, os Estados Unidos saíram da guerra em 1945 
com sua produção industrial extremamente aquecida, produção esta que o seu mercado interno não poderia absorver. Precisavam, então, buscar consumidores para seus produtos fora de suas fronteiras, e a Europa era o principal alvo. No entanto, diferentemente dos EUA, os países europeus viveram a guerra em seu solo e foram devastados por ela, não tendo capacidade financeira para comprar os produtos industrializados estadunidenses, concentrando seus esforços em alimentar a população e reconstruir seus países. É buscando solucionar esses problemas que se organizou uma reunião com os principais países capitalistas em Bretton Woods, nos Estados Unidos em 1944. O objetivo principal era instituir regras comuns e organismos internacionais que ajudassem a regular o sistema monetário internacional e, consequentemente, o comércio entre os países. Após intensos debates e a apresentação de propostas, decidiuse pela criação de dois organismos internacionais, o Banco Internacional de Reconstrução e Desenvolvimento (BIRD), com o objetivo de auxiliar no desenvolvimento da infraestrutura das nações necessitadas e o Fundo Monetário Internacional (FMI), responsável pela organização monetária e regulação comercial dos países-membros, além da adoção do dólar como moeda internacional. "No entanto, as duas instituições oriundas dos arranjos de Bretton Woods, a despeito das modificações que possibilitaram, não foram capazes de promover a reconstrução da Europa. O maior entrave existente era a escassez de dólares. Os EUA tinham a maior parcela da capacidade produtiva mundial e, entre 1946 e 1947, tiveram um excedente de produção, ao passo que a Europa não dispunha de dólares para efetuar a compra dos produtos norte-americanos. Se esse quadro não fosse alterado, tanto a Europa enfrentaria diversos problemas para se recuperar como também os EUA teriam sua economia desaquecida" (SIMON, 2011, p. 33). Foi aí que entrou em cena o Plano Marshall, que assim ficou conhecido por conta do seu idealizador, George Marshall, Secretário de Estado dos Estados Unidos durante a administração Truman.

4 Original em inglês. Todas as traduções deste texto foram realizadas por seu autor.

5 Hoje, esses cartazes estão todos em exibição permanente no George C. Marshall Museum, em Lexington, Virginia, Estados Unidos. No sítio eletrônico do museu, onde também estão disponíveis para consultas todos os cartazes, lê-se: "Esses pôsteres foram projetados para promover a ideia de coesão da Europa Ocidental e a integração dos países com a remoção de barreiras de comércio e instituições de ajuda intergovernamentais de comércio" (MARSHALL, 2014, [s. p.]).

6 A referência aqui é ao conceito desenvolvido por Benedict Anderson, ainda que em contexto e situação distintos. A analogia se faz possível pois, tal como Anderson pensa o conceito de nação, a formação de um bloco hegemônico que partilha de instituições econômicas, militares e culturais, também possui um sentimento de pertença comum que tem raízes em uma construção cultural. Assim percebo a ideia de Comunidade Atlântica e, posteriormente, Mundo Ocidental, como uma construção imagética, que não possui organização política, fronteiras definidas ou mesmo uma história comum, mas baseia-se em uma partilha de valores, ideais e sentimentos de pertença comuns, ou seja, de uma imagem mental de unidade. Isso não implica dizer que ela seja ilusória ou irreal. Ao contrário, ela se realiza no campo do simbólico e nele constitui subjetividades. Em última instância, para citar Anderson, "[...] ela é imaginada pois, mesmo os membros da mais minúscula nação jamais conhecerão, encontrarão ou sequer ouvirão falar da maioria de seus companheiros, embora todos tenham em mente a imagem viva da comunhão entre eles" (ANDERSON, 2008, p. 32). Cabe ressaltar, no entanto, que tal comunhão não suplanta outras comunidades imaginadas, tais como a nação ou outras existentes dentro dessa mesma comunidade, mas funciona em diálogo e, por vezes, em conflito com estas.

7 Faço aqui novamente menção ao apelo de Winston Churchill a uma comunhão dos países de língua inglesa, já discutido anteriormente neste capítulo.

8 Com a divisão da Alemanha em quatro setores administrativos, instituída da Conferência de Potsdam, em 1945, a cidade de Berlim, apesar de fazer parte da área sob administração soviética, por sua importância como capital do país, também sofreu a mesma repartição. Em 1948, as áreas da cidade controladas pelas potências ocidentais optaram por adotar o Marco Alemão como moeda principal em suas respectivas zonas, pressionando o restante da cidade a fazer o mesmo. Por não haver concordado com a medida, Stálin optou por bloquear totalmente o acesso à cidade pela via terrestre, impedindo assim a chegada de produtos e suprimentos dos países ocidentais às suas respectivas áreas de influência. A medida causou atritos entre os líderes dos dois lados da conjuntura bipolar, o que gerou receios do recurso às armas para solucionar o caso, fato que não ocorreu. A solução dada pelas potências democráticas liberais foi o uso do abastecimento aéreo, o que terminou por levar ao fim do bloqueio pouco menos de um ano depois de seu início.

9 A composição do grupo era bastante heterogênea, contando com ex-comunistas, socialistas críticos do estalinismo e mesmo alguns liberais. No entanto, em geral, procuravam seguir uma linha mais à esquerda. Entre os membros desse grupo, estavam os críticos Dwight MacDonald, Mary McCarthy, o compositor Nicolas Nabokov e o jornalista Arnold Beichman. Para mais informações sobre o grupo e sua organização, vide Warner (1995).

10 Apesar do aparente progressismo e da liberdade do grupo, vale salientar que o objetivo principal era a arregimentação dos intelectuais para o lado capitalista. Buscava-se mostrar o lado soviético como uma via impensável e eliminar quaisquer possibilidades de terceira via, que deveriam ser sugadas para dentro do espectro ocidental. Ou seja, de uma forma quase paradoxal, 
usava-se o discurso da liberdade como um captador de dissidências. Uma estratégia que, com algumas fissuras, teve resultados de longo prazo.

11 Assim foi como ficou conhecido um caloroso e improvisado "bate-boca" entre Nixon e Khrushchev, através de seus intérpretes, quando da abertura da Feira de Moscou. Em seu passeio pelos pavilhões para apresentar as novidades de consumo e a vida cotidiana do estadunidense comum para o líder soviético, Nixon procurava ressaltar as vantagens do livre mercado e da produção em massa, que, dizia ele, eram vantajosos para todos. Diante dessas apresentações, Khrushchev rebatia, ora falando das desigualdades sociais e do trabalho escravo mascarado em liberdade do modelo capitalista, ora argumentando que os soviéticos haviam lançado o Sputnik, e, portanto, estavam à frente dos Estados Unidos em tecnologia e, assim que concluíssem os investimentos no que era mais importante, em cinco ou seis anos ultrapassariam os Estados Unidos também nos bens de consumo. A batalha perdurou durante toda exposição, causando alguns momentos de desconforto para os tradutores e os demais membros das comitivas que os acompanhavam. O debate concluiu com uma cena de aparente bom humor de ambos, quando a guia estadunidense apresentou o circuito fechado de TV projetado para exibir as atividades em cada canto de uma das casas modelo e o líder soviético disparou: "Isto deve estar sempre quebrado", ao que o vice-presidente estadunidense respondeu "Naaa", e ambos sorriram.

12 Cabe chamar a atenção para a historicidade dos eventos aqui comparados. Não estou tentando sustentar uma continuidade entre o imperialismo europeu do século XIX e as políticas estadunidenses durante a Guerra Fria. Ao contrário, defendo que se tratam de eventos históricos específicos, cada qual elaborado por condições de possibilidade histórica diversas, ainda que possuam algumas semelhanças. Como bem colocou Christina Klein, "enquanto muitas representações estadunidenses sobre a Ásia produzidas antes da Segunda Guerra Mundial encaixam confortavelmente no modelo do orientalismo de Said, muitas representações do Pós-Guerra da Ásia comunista não se encaixam, ainda que não se contradigam inteiramente. A razão para isso reside na evolução do entendimento estadunidense da Raça”. (KLEIN, 2003, p. 11). A comparação que proponho aqui vai um pouco mais além e diz respeito à relação saber/poder e como foram utilizadas como mecanismos de enunciação de políticas específicas dentro de uma geopolítica de poder mundial. Assim, tanto a construção do oriente pela Europa no século XIX descrita por Said como a enunciação de um bloco atlântico pelos EUA no período em questão dizem respeito a políticas enunciativas elaboradas na alteridade e que visam à afirmação de si pela definição do outro enquanto um elemento inferior que deve ser guiado ao caminho correto ou mais positivo.

\section{Referências}

ANDERSON, Benedict. Comunidades imaginadas. Reflexões sobre a origem e a difusão do nacionalismo. São Paulo: Cia das Letras, 2008.

CHARTIER, Roger. À Beira da Falésia: a história entre certezas e inquietude. Porto Alegre: UFRGS, 2002.

DE GRAZIA, Victoria. America's advance through $\mathbf{2 0}^{\text {th }}$ century Europe. Cambridge: Belknap Press of Harvard University Press, 2005.

KENNEDY, Paul. Ascenção e queda das grandes potências: transformação econômica e conflito militar de 1500 a 2000. Rio de Janeiro: Campus, 1989.

KLEIN, Christina. Cold War Orientalism: Asia in the middlebrow imagination, 1945-1961. University of California Press, 2003.

MARSHALL Plan And The Poster Contest. 24 oct. 2014. Disponível em: http://marshallfoundation. org/blog/marshall-plan-poster-contest/. Acesso em: 18 abr. 2015.

MARLING, Karal Ann. As seen on TV: the visual culture of everyday life in the 1950s. Cambridge, Massachussets: Harvard University Press, 2000.

MORRAY, Joseph P. Origens da Guerra Fria. Rio de Janeiro: Zahar Editores, 1961.

MUNHOZ, Sidnei J. Ecos da Emergência da Guerra Fria no Brasil 1947-1953. Revista Diálogos, Maringá, v. 6, p. 41-59, 2002.

SAID, Edward W. Orientalismo: o Oriente como invenção do Ocidente. São Paulo: Companhia das Letras, 2007.

SAUNDERS, Frances Stonor. The Cultural Cold War: The CIA and the world of arts and letters. New York: The New Press, 2000.

SELEÇÕES READER'S DIGEST. Edições mensais de 1950 a 1960. Edição Brasileira. Disponível em: https://www.selecoes.com.br. Acesso em: 8 fev. 2019. 
SELEÇÕES READER'S DIGEST, jun. 1948, p. 44-46.

SIMON, Silvana Aline Soares. De Bretton Woods ao Plano Marshall: a política externa norte-americana em relação à Europa (1944-1952). Relações Internacionais no mundo atual, v. 2, n. 14, p. 24-47, 2011.

TUDO SIM É HISTÓRIA. [s. d.]. Disponível em: http://tudosimehistoria.blogspot.com. Acesso em: 8 fev. 2019.
WARNER, Michael. Origins of the Congress for Cultural Freedom, 1949-1950. Studies in Intelligence, v. 38. n. 5, ano 10, p. 89-97, 1995. Disponível em: https://www.cia.gov/library/centerfor-the-study-of-intelligence/kent-csi/vol38no5/ pdf/v38i5a10p.pdf. Acesso em: 8 fev. 2019. 